\title{
PIKETTY, FinANSALLAŞMA Ve YöNETici ÜCRETLERI
}

Piketty oldukça ilgi çeken kitabı 21. Yüzyılda Sermaye'de savaş gibi istisnai dönemler hariç kapitalist bir ekonominin normal işleyişinin her zaman eşitsizliğin artması ile sonuçlanacağını sermayenin getirisinin uzun dönemli olarak ekonomik büyümeden daha fazla olması ile açıklıyor. Konutlar, arsalar, makineler ve finansal araçlar gibi tüm servet unsurlarının dâhil edildiği sermaye büyüdükçe kendisini daha hızlı yeniden üretiyor ve sermaye gelirlerinin toplam gelirden aldığ pay artıkça toplumdaki gelir eşitsizliği büyüyor. Piketty kapitalist ekonominin bu yasasının ortaya çıkardığı sonucu düzeltmenin yolu olarak ise küresel artan oranlı bir servet vergisi öneriyor.

Her ne kadar sermaye birikimini ve yoğunlaşmasını uzun dönemli eşitsizlik artışının arkasındaki temel dinamik olarak görse de, Piketty 1980'den bugüne kadar geçen sürede artan eşitsizliğin önemli bir nedeni olarak emek gelirlerinin dağılımına işaret ediyor. Geçtiğimiz birkaç on yılda başta AngloSakson ülkeler olmak üzere ücret gelirleri gittikçe artan oranda eşitsiz dağılmış, bu da toplam gelir dağılımında bozulmanın esas nedeni olmuştur. Öyle ki ABD'de bu dönemde eşitsizlik artışının üçte ikisi emek gelirlerinin dağılımından kaynaklanırken yalnızca kalan üçte birlik kısım sermaye gelirlerinin dağılımından kaynaklanmıştır. Bunun dikkat çekici göstergesi ise en yüksek yüzde onluk dilimin ABD'de 1970'de toplam ücret gelirlerindeki pay1 \%25 iken, bu oranın 2010 sonu itibariyle \%35'e çıkmış olmasıdır. Bu artıştan en çok faydalanan tepedeki binde birlik diliminin ise \%70'ini üst düzey yöneticiler oluşturmaktadır.

ABD'ye göre daha düşük olmakla birlikte Birleşik Krallık ve Kanada gibi diğer Anglo-Sakson ülkelerde de yüksek ücretli şirket yöneticilerinin artan gelirlerinin etkisi ile benzer bir eğilim ortaya çıkmaktadır. Fransa, İsveç, Almanya gibi kara Avrupası ülkeleri ile Japonya'da ise son yıllarda üst düzey yöneticilerin ve \%1'lik kesimin gelirinde artış görülmekle birlikte bu çok daha sınırlı bir düzeydedir. 
Neden tamamı gelişmiş kapitalist ekonomiler olan bu ülkeler arasında üst düzey yöneticilerin ücretlendirilmesi ve en yüksek \%1'lik kesimin toplam gelirden aldığı pay konularında 1980 sonrası dönemde bir farklılaşma olmuştur?

Piketty kendi cevabını vermeden önce marjinal verimlilik teorisini ele alıyor. Ancak her iki ülke grubu da ileri teknolojiye dayalı üretim yaptığı ve uzun dönemli ekonomik büyüme oranları birbirine yakın olduğu için, bu farklılığı ABD'deki şirket yöneticilerinin bireysel verimliliklerinin daha yüksek olması ile açıklamaya çalışan marjinal verimlilik yaklaşımını fazla naif buluyor. $\mathrm{Bu}$ naifliği aşmak için kendi önerdiği teorinin merkezine ise ülkelerdeki sosyal norm farklılıklarını koyuyor. ABD ve Birleşik Krallık'ta 1970 sonrası ortaya çıan sosyal normlar şirketlerin üst düzey yöneticilerinin şirkete daha fazla katkı koymalarını ve buna uygun olarak daha cömert bir gelir elde etmelerini tolere edebilirken, aynı sosyal normlar diğer ülkelerde ancak son zamanlarda kabul görmeye başladığı için bu yönde bir eğilim de daha geç ortaya çıkmıştır diyor.

Artan oranlı gelir vergisini tartışırken bu konuya geri dönen Piketty, ikinci bir açıklama daha yapıyor. 1980 sonrası dönemde en yüksek gelir dilimine uygulanan vergi oranlarının düşmesi ile en yüksek \%1'lik kesimin gelirinin artması arasında bir ilişki tespit ediyor. Buna göre vergi oranlarını daha çok düşüren ülkelerde en yüksek gelir sahiplerinin payı daha hızlı artıyor. Vergi gelirleri içinde hiçbir dönem önemli bir yer tutmayan en yüksek gelirlilere uygulanan çok yüksek vergi oranları (\%80-90) devletler tarafindan gelir elde etme amacından çok yüksek gelirleri caydırmaya yönelik bir uygulama olarak düşünülmüştür. Piketty, bu oranların önemli düzeyde düşürülmesiyle üst düzey şirket yöneticilerinin ücretlerinin belirlenmesi yönteminin değiştiğini, pazarlık güçlerinin arttığını ve şirket yönetim kurulları ile hisse sahiplerini yüksek ücretlere ikna etmelerinin daha kolaylaştığını iddia ediyor.

Piketty nasıl marjinal verimlilik teorisini naif buluyor ise, ABD ve diğer Anglo-Sakson ülkelerdeki toplumların yüksek ücretleri daha kabul edilebilir bulduklarını içeren kendi önerdiği sosyal normlar yaklaşımını da "naif" bulmak mümkün görünüyor. Vergi oranları da önemli bir rol oynamakla birlikte, kitapta sunulan verilerden de görülebileceği üzere, aslında bütün ülkelerde 1980 sonrası dönemde bu oranlarda önemli düşüşler gözlenmiştir. Dolayısıyla, bu iki ülke grubu arasında vergi oranlarının düşmesinin üst düzey yönetici ücretleri üzerinde yarattığı etkinin farklılaşması ek bir açıklamayı daha hak ediyor. 


\section{Şirket ortağı olarak sermaye sahipleri}

Bugün bildiğimiz anlamda şirketlerin ve sermaye piyasalarının gelişmesinin en önemli evrelerinden birisi, şirketlerin anonim ortaklıklar olarak örgütlenmeye başlamasıdır. Şirketin sermayesi hisse senetleri ile temsil edilen paylara ayrılmakta, farklı kişiler bu senetleri satın alarak şirketlere ortak olmakta ve şirketin malvarlığı ve hesapları ile ortakların malvarlıkları ve hesapları birbirinden ayrılmaktadır. Günümüzde istisnai formlar olmakla birlikte halka açı şirketler esas olarak birer anonim ortaklıktır ve hisse senetleri (payları) borsalarda el değiştirmektedir.

Ancak borsalarda işlem gören şirketlerin sermaye yapıları arasında önemli farklılıklar vardır. Bu farklılığın temelinde ise bazı şirketlerde şirketi kontrol eden (oy çokluğu ile kararlarına yön verebilen) ortaklar varken, diğerlerinde şirketi kontrol edebilen ortak(lar) bulunmaması yatmaktadır. Bir halka açık şirketin sermaye yapısına ilişkin önemli gösterge borsada işlem gören hisselerinin şirketi kontrol eden ortağa ait paylar dışında kalan kısmının toplam şirket sermayesine oranıdır. Halka açıklık oranı olarak tanımlayabileceğimiz bu gösterge, Piketty'nin işaret ettiği iki ülke grubu arasında önemli bir farklılığa işaret etmektedir.

ABD ve Birleşik Krallık gibi ülkelerde şirketlerin halka açıklık oranları \%90'nın üzerinde iken, aynı oran Fransa, Almanya ve Japonya'da \%70'ler düzeyindedir1. Tek başına yeterli olmamakla birlikte bu oranlar bize ilk gruptaki ülkelerde şirketlerde dağınık ortaklık yapısının, ikinci gruptaki şirketlerde ise kontrolün olduğuna ilişkin güçlü bir gösterge sunmaktadır. Uluslararası karşılaştırmalarda da Anglo-Sakson ülkeler şirketlerde kontrol gücünü elinde bulunduran ortağın olmadığı, dağınık ortaklık yapısının olduğu ülkeler olarak tanımlanmaktadır ${ }^{2}$. Örneğin, ABD'de bir borsada işlem gören en büyük 1500 şirketin sadece $\% 8$ 'inde (114 şirket) şirketi kontrol eden bir ortak bulunurken, bu oran Fransa'da işlem gören şirketler için \%86'dır. ${ }^{3}$

Berle ve Means'in 1932 yılında yayımlanan ve bugünkü kurumsal yönetim ve şirketlerin ortaklık yapısı tartışmasının referans noktası olarak

\footnotetext{
${ }^{1}$ Goldman Sachs (2010), "EM Equity in Two Decades: A Changing Landscape", Global Economics Paper, No: 204, September. Bekeart, G. ve Harvey, C.R. (2013), Emerging Equity Markets in a Globalizing World

${ }^{2}$ IOSCO (2007), Board Independence of Listed Companies, Technical Committee of the International Organization of Securities Commission.

${ }^{3}$ IRRC ve ISS (2012), Controlled Companies in the Standard \& Poor's 1500: A Ten Year Performance and Risk Review, IRRC Institute, New York. OECD (2012), Related Party Transactions and Minority Shareholder Rights, OECD Publishing
} 
kabul edilen kitaplarında ${ }^{4}$ dahi ABD'de şirket sahipliğinin gittikçe dağınık bir hal almasının etkilerini tartıştıklarını dikkate alırsak, Anglo-Sakson ülkeler ile diğer ülkeler arasındaki şirket ortaklığı yapısındaki farklılığın son dönemde ortaya çıkan bir olgu olmadığını kabul edebiliriz. Ancak son dönemde şirket ortaklarının karakterinde dikkat çeken bir değişim yaşanmıştır.

\section{Sermaye "sahibi" olarak kurumsal yatırımcılar}

Kurumsal yatırımcılar terimi genel olarak gerçek kişiler, finansal olmayan şirketler ve bankalar dışında kalan finansal piyasa yatırımcılarını tanımlamak için kullanılsa da kapsamı konusunda tam bir fikir birliği olduğu ileri sürülemez. İki önemli alt kategori ise geleneksel kurumsal yatırımcılar olarak adlandırılan emeklilik fonları, yatırım fonları ve sigorta şirketleri ile geçtiğimiz on yıllarda ortaya çıkan ve hızlı bir gelişme gösteren alternatif biçimler olan ulusal varlık fonları ile girişim ve risk sermayesi şirketleridir.

Özellikle ulusal varlık fonları büyük oranda gelişmiş ülkeler dışında kalan devletlerin kontrolünde olmalarının yarattığ 1 politik tartışmaların etkisiyle, Piketty'nin de ayrı bir başlık altında ele almaya gerek göreceği kadar, ilgi uyandırmaktadırlar. Bu fonların toplam varlığının son beş yılda neredeyse $\% 50$ oranında arttı̆g 1 ve 2013 yılı sonu itibariyle 6 trilyon ABD dolarına ulaştı̆g tahmin edilmektedir. ${ }^{5}$

Ancak bu hızlı artış oranı ve yürütülen tartışmalar ulusal varlık fonlarının küresel düzeyde toplam kurumsal yatırımcı varlıklarının küçük bir kısmını kapsadığı gerçeğini gölgelememelidir. Geleneksel ve alternatif kurumsal yatırımcıların toplam varlıklarının 2011 yılı sonu itibariyle 85 trilyon $\mathrm{ABD}$ doları olduğu tahmin edilmekte ve bunun \%6'dan daha küçük bir kısmı ulusal varlık fonları tarafindan kontrol edilmektedir. Toplam tutarın neredeyse yarısı (\%47) Anglo-Sakson ülkelerdeki emeklilik ve yatırım fonları ile sigorta şirketleri varlıklarından oluşmakta ve gelişmiş ülkeler dışında -ulusal varlık fonları hariç olmak üzere- hiçbir kurumsal yatırımcı modeli önemli bir varlık göstermemektedir. Diğer dikkat çekici husus ise her ne kadar ulusal varlık fonları kadar olmasa da özellikle Anglo-Sakson ülkelerde yoğunlaşan

\footnotetext{
${ }^{4}$ Berle A. A. ve Means G. C. (1932), The Modern Corporation and Private Property

${ }^{5}$ Sovereign Wealth Funds Institute, Fund Rankings, www.swfinstitute.org. Ulusal varlık fonlarına ilişkin referans veri olarak genellikle SWF Institute'ün toplam varlık değeri rakamları kullanılsa da bunların tahmine dayandığı ve ciddi eleştiriye muhatap olduğunu hatırlatmakta fayda var. Örneğin, IMF bu hesaplamanın bazı ülkeler için merkez bankası rezervlerini de kapsaması nedeniyle oldukça yüksek olduğunu ifade etmektedir. IMF (2012), Global Financial Stability Report, April
} 
geleneksel fonlar 2000 yılı sonrası dönemde önemli oranda büyümüştür ( $2000=36$ trilyon ABD doları, 2011=73 trilyon ABD doları). ${ }^{6}$

Bir ekonomide finansal piyasaların, finansal piyasa aktör ve kurumlarının ve finans odaklı karar alma motiflerinin rolünün artması olarak tanımlanan finansallaşma ${ }^{7}$ sürecinin küresel düzeyde önemli bir bileşeni sermayenin gittikçe artan oranda kurumsal yatırımcı formundaki finansal aracılar eliyle yönetilmesidir. Bunun en önemli sonuçlarından birisi ise finansal sektör dışındaki şirketlerin sahipliğinin önemli oranda gerçek kişilerden bu finansal aracılara kayması olmuştur. Örneğin 1960'larda gerçek kişiler (hanehalkları) ABD'de halka açık şirketlerin toplam sermayesinin \%84'ünü elinde tutarken, bu oran 2011 yılı sonu itibariyle \%40'a düşmüştür. Benzer dönemde İngiltere'deki düşüş ise \%54'ten \%11'e olmuştur. ${ }^{8}$ Bugün ABD, İngiltere ve Kanada'da halka açık şirketlerin sermayelerinin büyük kısmı birer finansal şirket olan kurumsal yatırımcılar tarafından kontrol edilmektedir.

Küresel düzeyde halka açık şirketlere ilişkin düzenlemelerin referans kaynağı olarak görülen ve ilk defa 1999 yılında kabul edilen OECD Kurumsal Yönetim Illkeleri hanehalklarının doğrudan şirket ortaklığından finansal kuruluşların aracılığıyla ortak olmalarına evrilen bu süreci olumlu karşılamıştı. ${ }^{9}$ Bunun altındaki temel gerekçe ise finansal yatırımcıların kurumsal kapasiteleri ve yatırımlarının büyüklüğü nedeniyle bireylere göre şirket ortağı olmaktan kaynaklanan haklarını daha iyi kullanacakları ve şirket yönetimlerini gözetim altında tutacakları beklentisiydi. Ancak OECD'nin finansal krizin nedenlerine ilişkin kendi değerlendirmesinde de işaret ettiği üzere bu beklenti büyük oranda gerçekleşmedi. ${ }^{10}$

$\mathrm{Bu}$ beklentinin gerçekleşmemesinin ve aynı zamanda ekonomilerin finansallaşmasının iki temel dinamiğinden birisi finansal piyasaların işleyişini değiştiren teknolojik ilerlemeler iken diğeri 2000'li yıllarda pek çok ülkede

\footnotetext{
${ }^{6}$ Çelik, S. ve M. Isaksson (2013), "Institutional Investors as Owners: Who Are They and What Do They Do?", OECD Corporate Governance Working Papers, No. 11, OECD Publishing.

${ }^{7}$ Epstein, G. A. (2005); Financialization and the World Economy, Edward Elgar Publishing, UK

${ }^{8}$ Çelik, S. ve M. Isaksson (2013)

${ }^{9}$ OECD (2004), Principles of Corporate Governance, Preamble.

${ }^{10}$ OECD (2010), Corporate Governance and the Financial Crisis: Conclusions and Emerging Good Practices to Enhance Implementation of the Principles, OECD Steering Group on Corporate Governance, OECD, Paris
} 
finansal piyasaların serbestleşmesi amacıyla yapılan düzenlemeler oldu ${ }^{11} . \mathrm{Bu}$ gelişmelerin sonucunda şirketlere ilişkin finansal ve diğer bilgilere değil bilgisayar modellerine dayanan yatırım yöntemleri ağırlık kazandı, çok sayıda şirkete aynı anda yatırım yapma imkânı veren finansal araçlar geliştirildi ve kurumsal yatırımcılar gittikçe artan sayıda şirkete aynı anda yatırım yapmaya başladı. Örneğin, 2012 yılı itibariyle 237 milyar ABD doları büyüklüğe ulaşan ABD'nin en büyük emeklilik fonu olan Kaliforniya Kamu Çalışanları Fonu (CalPERS) yaklaşık yarısı ABD'de ve yarısı ABD dışında olmak üzere on bin şirkette hisseye sahip durumdaydı. ${ }^{12}$ Ayrıca artan oranda bu varlıkların yönetimini varlık yönetiminde uzmanlaşmış diğer finans sektörü şirketlerine devretmekte, bu kapsamda sadece halka açı şirketlerdeki hisse senedi yatırımlarını yönetmek üzere 40 varlık yönetim şirketi ve 296 aracı kurum ile çalışmaktaydı. ${ }^{13}$

Geleneksel kurumsal yatırımcıların varlık yönetimlerini diğer finansal kurumlara devretmesine benzer bir gelişme, şirket genel kurullarında oy kullanma uygulamalarına da yansıdı. Bu kurumlar oy kullanmayı büyük oranda mekanik bir sürece indirgeyen ve şirketler özelinde değerlendirme yapma imkânı sınırlı olan danışmanlık şirketlerine devrettiler. $\mathrm{Bu}$ uygulama sonucunda genel kurullarda ABD ve İngiltere gibi çok dağınık ortaklık yapısının olduğu şirketlerde dahi yüksek katılım oranları gözlenirken, ortakların kararlara katılım düzeyi tartışma konusu oldu. Öyle ki üst yönetimin ve ücretlerinin belirlenmesinin de dâhil olduğu kararlara onay vermeme oranı hiçbir ülkede \%6'yı aşmamaktır. Örneğin, bazı bankaları iflasa sürükleyen tartışmalı kararlarda dahi şirket ortakları kararlara ancak \%5'ler düzeyinde muhalefet etmişlerdir. ${ }^{14}$

\section{Sermayesiz sahiplik}

Basit ifadesiyle, başta ABD ve İngiltere olmak üzere Anglo-Sakson ülkelerde son on yillarda şirket sermayelerinin çok büyük bir kısmına finansal kuruluşlar aracılığıyla sahip olunmaya başlandı; ancak bunların çok sayıda

\footnotetext{
${ }^{11}$ ABD'de Regulation NMS ve AB'de MiFID bu düzenlemelere örnek olarak verilebilir.

${ }^{12}$ CalPERS Annual Investment Report, Financial Year Ended June 30, 2012

${ }^{13}$ CalPERS Comprehensive Annual Financial Report, Financial Year Ended June 30, 2012

${ }^{14}$ Isaksson, M. ve S. Çelik (2013), "Who Cares? Corporate Governance in Today's Equity Markets", OECD Corporate Governance Working Papers, No. 8, OECD Publishing.
} 
şirkete birer finansal yatırım olarak aynı anda ortak olmaları ve tekil şirketlerin işleyişine dâhil olmamaları nedeniyle şirketlerin yönetiminde çoğu ilgili şirkete önemli sermaye sahip olmayan üst yönetim hâkim durumdadır. $\mathrm{Bu}$ üst yönetimlerin ücretlerini belirlemelerine ilişkin şirket içi mekanizmalar kurulsa da bunların pratikteki işleyişi yöneticilerin kendi ücretlerini kendilerinin belirlemesi oldu. Özellikle ABD'de fiili olarak şirket ortaklarının yönetim kuruluna aday önerme hakkının olmadı ̆̆ı, ancak beğenmedikleri adaya itiraz edebildikleri ve şirketlerin çoğunda yönetim kurulu başkanı ile genel müdürün aynı olduğu dikkate alındığında, ${ }^{15}$ şirketlerin hâkim ortağ 1 olmayan genel müdürler temel karar alıcı konumdadırlar.

Almanya, Fransa ve İsveç gibi kara Avrupası ülkeleri ile Japonya'da da kurumsal yatırımcıların ağırlı̆ğının artması ve yatırım yöntemlerinin değişmesi yönünde eğilimler gözlemlense de hâlihazırda bu ülkelerdeki halka açık şirketlerin çok önemli bir kısmında üst yönetim ücretleri de dâhil olmak üzere karar verme gücü olan hâkim ortaklar bulunmaktadır. Doğrudan önemli ekonomik çıkarı olan hâkim ortağın varlığı, üst yönetim ücretlerinin artışının sınırlı kalmasında önemli bir etken olmaktadır.

Finansal krizi takiben, krizin ana etkenlerinden de birisi olarak görülen üst düzey yöneticileri daha yüksek risk almaya iten ücretlendirme yöntemlerine ilişkin önemli tartışmalar yürütülmüş ve pek çok düzenleme yürürlüğe konmuştur. ABD'de Dodd-Frank yasasıyla gelen bu düzenlemeler ile ağırlıklı olarak üst düzey yönetimin ücretlerinin belirlenme yönteminin ve tutarlarının ortaklara açıklanması ve ortakların karar alma süreçlerine katılması ve bu vesile ile artışın kontrol edilmesi hedeflense de, sonuçlar aksi yönde olmuştur. Krizden bugüne kadar geçen sürede ABD'de ortalama genel müdür ücreti ortalama şirket çalışanı ücretinin 2009 yılında 193 katından 2013 yılında 296 katına kadar yükselmiştir. ${ }^{16}$ İlginç bir deneyim ise İsviçre'de bir şirket içindeki en yüksek ücreti en düşük ücretin 12 katı ile sınırlamayı öneren düzenlemenin 2013 yılında gerçekleşen referandum ile reddedilmesi oldu. Hâlihazırda AB de dâhil olmak üzere yönetici ücretlerinin düzenlenmesi konusunda pek çok çalışma yapılmakla birlikte, somut bir ilerleme olmamıştır.

Başta ABD'de üst yönetime ücret olarak verilen ve bugün gelirlerinin önemli bir kısmını oluşturan hisse senedi opsiyonlarına vergi avantajı getirilmesi uygulaması olmak üzere, ${ }^{17}$ vergisel değişikliklerin gelir dağılımını

${ }^{15}$ OECD (2012), Board Member Nomination and Election, OECD Publishing.

${ }^{16}$ Mishel L., Davis A (2014), CEO Pay Continues to Rise as Typical Workers Are Paid Less, Economic Policy Institute

${ }^{17}$ ABD'de 1984 yllında hisse senedine dayalı ödemeler bir yöneticinin gelirinin içinde neredeyse hiç pay almaz iken, 1991 yılında hisse senedine dayalı ödemelere getirilen 
bozacak oranda üst düzey yönetici ücretlerinin aşırı artmasına yol açmasında ilgili ülkelerde sermayenin kurumsallaşma karakteri ve ekonominin finansallaşma düzeyleri arasındaki farklılıklar önemli rol oynamıştır. Üst yöneticilerin ücretleri önemli oranda şirketlerin hisse senedi fiyatına endekslenmiş, sermayenin getirisinin yüksek olması mekanizması -hisse senetlerini sermayenin bir bileşeni olarak düşündüğümüzde- burada da işlemiş ve yöneticiler gittikçe artan oranda gelir elde etmeye başlamışlardır. Vergi indirimlerinin ücret artış1 yönünde güçlü bir etki oluşturması ücretlerin belirlenmesinin finansal piyasaların işleyişine bırakılması, finansal aracılar eliyle şirket sahipliğinin artması ve kapitalist sermaye birikiminin farklı örgütlenme biçimleri ile mümkün olmuştur.

Serdar Çelik, Ekonomist /Proje Yöneticisi, OECD.

\section{Kaynakça}

Bekeart, G. ve Harvey, C.R. (2013), Emerging Equity Markets in a Globalizing World

Berle A. A. ve Means G. C. (1932), The Modern Corporation and Private Property

CalPERS Annual Investment Report (2012), Financial Year Ended June 30, 2012

CaIPERS Comprehensive Annual Financial Report (2012), Financial Year Ended June 30, 2012

Çelik, S. ve M. Isaksson (2013), "Institutional Investors as Owners: Who Are They and What Do They Do?", OECD Corporate Governance Working Papers, No. 11, OECD Publishing.

Epstein, G. A. (2005); Financialization and the World Economy, Edward Elgar Publishing, UK

Goldman Sachs (2010), “EM Equity in Two Decades: A Changing Landscape”, Global Economics Paper, No: 204, September.

IMF (2012), Global Financial Stability Report, April

IOSCO (2007), Board Independence of Listed Companies, Technical Committee of the International Organization of Securities Commission.

IRRC ve ISS (2012), Controlled Companies in the Standard \& Poor's 1500: A Ten Year Performance and Risk Review, IRRC Institute, New York.

vergisel teşviklerden sonra bu oran 2001 yılında \%66 düzeyine kadar çıkmıştır. Stout L. (2012), The Shareholder Value Myth, Berrett-Koehler Publishers, USA 
Isaksson, M. ve S. Çelik (2013), "Who Cares? Corporate Governance in Today's Equity Markets", OECD Corporate Governance Working Papers, No. 8, OECD Publishing.

Mishel L., Davis A (2014), CEO Pay Continues to Rise as Typical Workers Are Paid Less, Economic Policy Institute

OECD (2004), Principles of Corporate Governance, Preamble.

OECD (2010), Corporate Governance and the Financial Crisis: Conclusions and Emerging Good Practices to Enhance Implementation of the Principles, OECD Steering Group on Corporate Governance, OECD, Paris

OECD (2012), Board Member Nomination and Election, OECD Publishing.

OECD (2012), Related Party Transactions and Minority Shareholder Rights, OECD Publishing

Piketty T. (2014), Capital in the Twenty-First Century, Çeviri:Arthur Goldhammer, The Belknap Press of Harvard University Press

Stout L. (2012), The Shareholder Value Myth, Berrett-Koehler Publishers, USA 